https://helda.helsinki.fi

\title{
Thermoresponsive Polycation-Stabilized Nanoparticles through PISA. Control of Particle Morphology with a Salt
}

\section{Baddam, Vikram}

2021-05-11

Baddam , V , Valinen , L \& Tenhu , H 2021 , ' Thermoresponsive Polycation-Stabilized Nanoparticles through PISA. Control of Particle Morphology with a Salt ' , Macromolecules, vol. 54 , no. 9 , pp. 4288-4299 . https://doi.org/10.1021/acs.macromol.0c02771

http://hdl.handle.net/10138/330872

https://doi.org/10.1021/acs.macromol.0c02771

cc_by

publishedVersion

Downloaded from Helda, University of Helsinki institutional repository.

This is an electronic reprint of the original article.

This reprint may differ from the original in pagination and typographic detail.

Please cite the original version. 


\title{
Thermoresponsive Polycation-Stabilized Nanoparticles through PISA. Control of Particle Morphology with a Salt
}

\author{
Vikram Baddam, Lauri Välinen, and Heikki Tenhu*
}

Cite This: Macromolecules 2021, 54, 4288-4299

Read Online

ABSTRACT: Poly[(vinylbenzyl) trimethylammonium chloride] (PVBTMAC) has been used as a stabilizer in the polymerizationinduced self-assembly polymerizations of diacetone acrylamide (DAAM). A whole spectrum of particle morphologies was obtained simply by adjusting the ionic strength of the reaction mixtures; no dilution of the cationic charges with noncharged comonomers or with noncharged polymers was needed. In addition to the ionic strength, the effects of solid content and the length of the PDAAM block on the morphologies of the particles were studied in detail. The experiments are a continuation

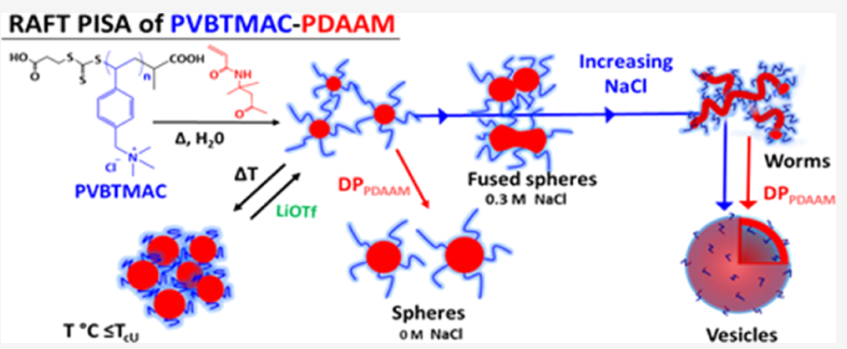
to previous studies on solution properties of PVBTMAC. It has been shown earlier that the solubility of the polycation may be tuned with counterions. Hydrophobic triflate ions induce an upper critical solution temperature behavior. In the present case, the chains bound to hydrophobic cores of the particles show either a one-step phase separation in aqueous triflate solutions or under certain conditions, a two-step transition. The step-wise transition is typical for responsive polymers with limited mobility.

\section{INTRODUCTION}

Amphiphilic block copolymers are able to build up various nano-objects such as spherical micelles, worm-like micelles, and lamellae or vesicles. ${ }^{1-3}$ The morphology of the nanoobjects depends on the ratio of the hydrophobic and hydrophilic block lengths, temperature, solvent composition, and chemical nature of the blocks. ${ }^{4,5}$ In charged block copolymers, the charge density of the polyelectrolyte blocks and their length influence the morphologies. ${ }^{6-9}$ Morphological changes may be induced by changing the $\mathrm{pH}$ or salt concentration. ${ }^{10-12}$

Ionic or nonionic copolymers may self-assemble during the polymerization process, preferably when controlled radical polymerization techniques are used in aqueous emulsions or in dispersions. ${ }^{13-19}$ A polymerization-induced self-assembly (PISA) technique has become a straightforward tool for synthesizing amphiphilic nano-objects with different morphologies. $^{20-25}$ In PISA, polymers self-assemble during the polymerization in which solvophilic chains are extended with another monomer that forms an insoluble block. The final morphology of the copolymer nanoparticles can be tuned by adjusting the reaction parameters. ${ }^{26-32}$

When synthesizing electrosterically stabilized nano-objects, the PISA technique often leads only to spherical structures. In the polyelectrolyte-stabilized particles, the growth of higherorder morphologies is limited due to the charge repulsion between ionic units. ${ }^{14,33-37}$ However, the higher-order morphologies in ionic copolymers have been achieved by reducing the charge repulsions. One way to reduce the charge density is to utilize stabilizers comprising randomly distributed ionic and nonionic repeating units. Another way is to use a mixture of charged and noncharged stabilizers. Worm-like micelles were obtained when statistical copolymers of acrylic acid and poly(ethylene glycol) methyl ether acrylate were chain-extended with styrene. ${ }^{38}$ Worms and vesicles were produced from copolymers of 2-hydroxypropyl methacrylate (HPMA), using a mixture of nonionic macro chain transfer agent poly(glycerol monomethacrylate) and anionic poly(potassium 3-sulfopropyl methacrylate). ${ }^{33}$ The addition of a cosolvent has also been used to promote higher-order morphologies in ionic copolymer systems. ${ }^{27,30,39-41}$ The final morphologies of the particles may also depend on parameters such as $\mathrm{pH}$, salt, solvent composition, stirring speed, and block ratio. $^{20,31,38,42}$

Few polycations have been used as macro chain transfer agents, macro-CTAs, in aqueous PISA to prepare charged nanoparticles. ${ }^{34,43,44}$ Recently, a polycation poly(2(acryloyloxy)ethyltrimethylammonium chloride), PATAC, was chain-extended with a core-forming monomer diacetone acrylamide (DAAM). Higher-order morphologies were achieved when the charge density in the corona was reduced using a binary mixture of PATAC and nonionic poly $(N, N$ -

Received: December 15, 2020

Revised: $\quad$ March 20, 2021

Published: April 22, 2021 
Scheme 1. Synthesis of Macro-CTA PVBTMAC (A) and Diblock Copolymer PVBTMAC-PDAAM (B) via RAFT Polymerization

(A) RAFT solution polymerization of VBTMAC<smiles>C=Cc1ccc(C[N+](C)(C)C)cc1</smiles>

(B) RAFT dispersion polymerization of DAAM
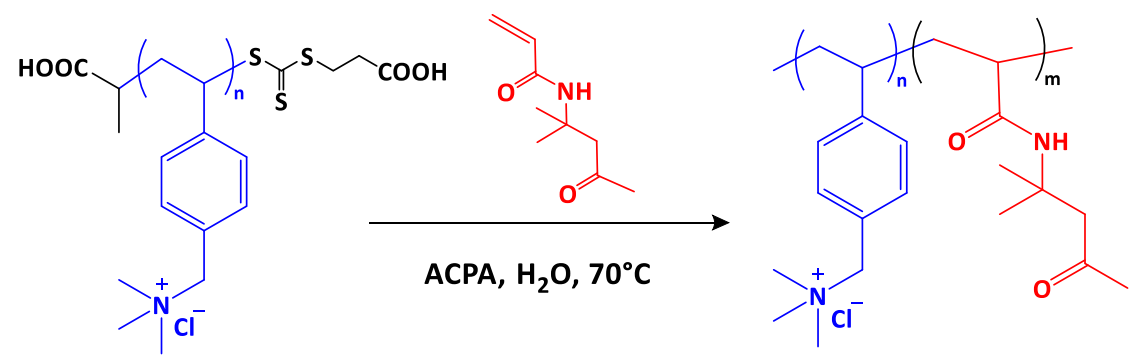

PVBTMAC-PDAAM

Diblock copolymer

dimethylacrylamide) as macro-CTAs. ${ }^{45}$ However, using sole polycations, only spherical particles have been observed when either the $\mathrm{pH}$ or salt concentration was varied. To date, access to higher-order morphologies in aqueous PISA by utilizing sole polycation stabilizers remains unattained.

In our recent studies, we have shown that the solubility of polycations in water can be changed with various salts. ${ }^{46-49}$ Depending on the cationic moiety and the counterion, the polycations phase-separate above the lower critical solution temperature (LCST) and/or below the upper critical solution temperature (UCST). Due to the aromatic units, polystyrenebased polycations undergo phase separation with a less amount of hydrophobic ions compared to more hydrophilic methacrylate-based polycations. ${ }^{47,48} \mathrm{We}$ envisioned that a styrenebased polycation, poly[(vinylbenzyl)trimethylammonium chloride] (PVBTMAC), could be used as a sole stabilizer in PISA to produce nanoparticles with cationic shells. The assumption was that the charge density in the corona layer can be easily reduced with salts. Interestingly, by introducing hydrophobic counter ions, it should be possible to turn the nanoparticles thermoresponsive.

Among the acrylamide-based water-miscible monomers, DAAM has been utilized in several PISA syntheses. ${ }^{45,50-52}$ Nonionic and/or ionic hydrophilic chains extended with DAAM build up nanostructures. In some of those, the particle morphologies may change with temperature and the core composition. $^{51,53}$ The ketone functionality of DAAM may be used for postpolymerization functionalization or for crosslinking the particle core. ${ }^{50,54}$

In this work, a cationic PVBTMAC macro-CTA was chainextended with DAAM. In order to allow sphere-sphere fusion and further evolution of particle morphologies, polymerizations were carried out in the presence of $\mathrm{NaCl}$. With a systematic increase in the salt concentration, morphological transitions from spheres to worms and vesicles were achieved. Various nanostructures in constant salt concentration were attained by varying the PDAAM length, as well as solid contents. In aqueous triflate solutions, the nanoparticles undergo a UCST-type phase separation similar to homopolymers of PVBTMAC. To the best of our knowledge, this is the first report on a cationic styrenic polymer as a single stabilizer block in PISA. Using PVBTMAC as the sole polycation stabilizer in PISA, one can induce morphological changes just by adding $\mathrm{NaCl}$. On the other hand, adding LiOTf (triflate) to the dispersions leads to the build-up of thermoresponsive particles.

\section{EXPERIMENTAL SECTION}

Materials. (Vinylbenzyl)trimethylammonium chloride [VBTMAC; 99\%], DAAM (99\%), chain transfer agent 2-(2carboxyethylsulfanylthiocarbonylsulfanyl)propionic acid (CTPA; 95\%), and 4,4'-azobis(4-cyanovaleric acid) (ACPA; $275 \%$ ) were used as received from Sigma-Aldrich. Sodium chloride $(\mathrm{NaCl})$ was purchased from Fisher Scientific ( $\geq 99.0 \%$ ), and trifluoromethanesulfonic acid lithium salt (LiOTf; 99.995\%, Sigma-Aldrich) and methanol (HPLC grade, $\geq 99.9 \%$ ) were also from Sigma-Aldrich. 1,1,1,3,3,3-Hexafluoro-2-propanol (HFIP) was received from Fluorochem. Deionized water was purified with an ELGA pure lab ultrapurification system. Regenerated cellulose membrane tubes (MWCO of $1 \mathrm{kDa}$ ) from Spectrumlabs and Maxi Pur-A-Lyzer dialysis tubes (MWCO 6-8 kDa) from Sigma-Aldrich were used for purification of polymers. All deuterated solvents were purchased from Eurisotop (Cambridge Isotope Laboratories, U.K.). 


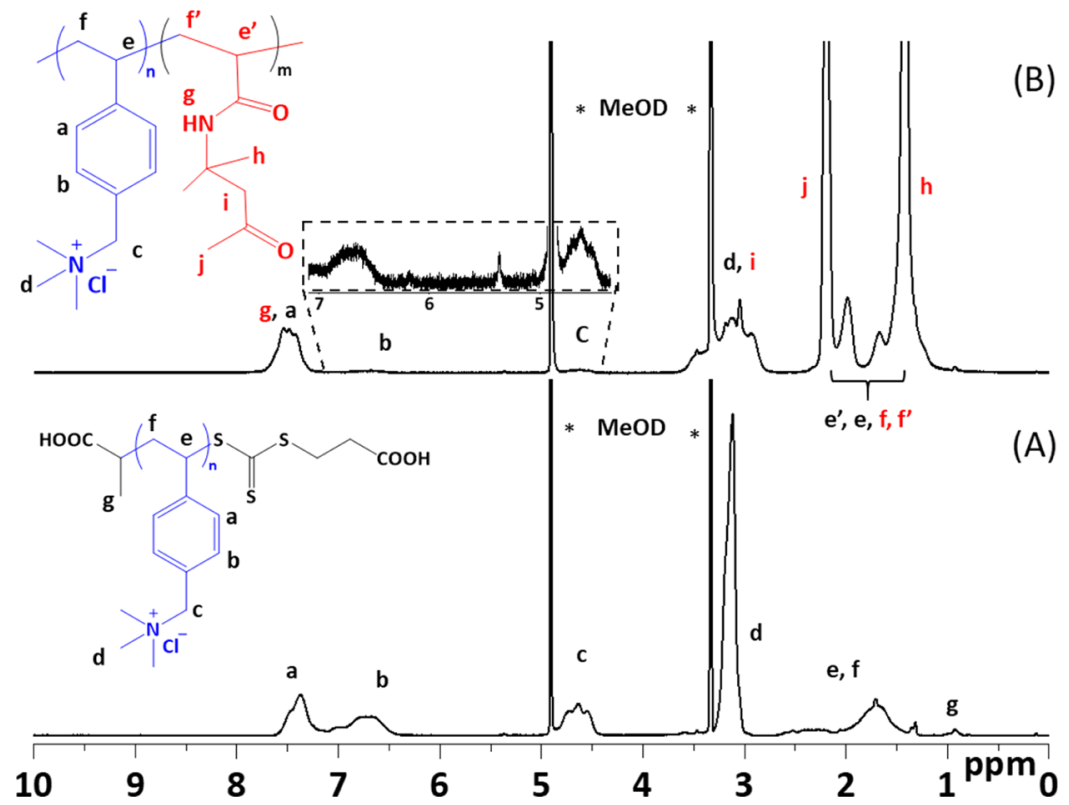

Figure 1. ${ }^{1} \mathrm{H}$ NMR spectra of PVBTMAC 27 (A) and diblock copolymer PVBTMAC-PDAAM (B) in MeOD- $d_{4}$.

Synthesis of Macro-CTA PVBTMAC via RAFT Solution Polymerization. In a typical synthesis, $3.008 \mathrm{~g}$ of cationic monomer VBTMAC $(0.0142 \mathrm{~mol}), 0.121 \mathrm{~g}(0.475 \mathrm{mmol})$ of CTPA, and ACVA $(40.7 \mathrm{mg}$, $0.145 \mathrm{mmol}$ ) were charged to a three-neck round-bottom flask $(250$ $\mathrm{mL}$ ). The precursors were dissolved in $30 \mathrm{~mL}$ of deionized water, and the reaction mixture was adjusted to acidic $\mathrm{pH}$ conditions. The sealed reaction mixture was purged with argon gas for $45 \mathrm{~min}$ and then transferred to a preheated oil bath at $70^{\circ} \mathrm{C}$. After $5 \mathrm{~h}$, the reaction was quenched by immersing in liquid nitrogen and then by exposure to air. The final conversion of the monomer, $82 \%$, was determined with ${ }^{1} \mathrm{H}$ NMR spectroscopy. The crude polymer was dialyzed against deionized water for 2 days with changing the water several times. Finally, pure macro-CTA PVBTMAC was collected by freeze-drying from aqueous polymer solution. A mean degree of polymerization (DP) was determined by end-group analysis with ${ }^{1} \mathrm{H}$ NMR and UV spectroscopy.

Synthesis of Block Copolymer Nanoparticles via RAFT Aqueous Dispersion Polymerization. Syntheses of diblock copolymer nanoparticles were first conducted in water by changing various parameters such as DPs of PDAAM, total solids, and salt concentrations. The syntheses are listed in Table S2 (entry 1-12), Table S3 (entry 1-3), and Table S4 (entry 1-4). For instance, the copolymer PVBTMAC $_{21}-$ PDAAM $_{216}$ diblock copolymer nanoparticles were prepared with $23 \mathrm{w} / \mathrm{w} \%$ solids in pure water as follows. In a reaction vial, $0.5 \mathrm{~g}(2.95 \mathrm{mmol})$ of DAAM, $64 \mathrm{mg}$ of PVBTMAC 21 macro-CTA (4725 g/mol; $13.54 \mu \mathrm{mol})$, and $0.83 \mathrm{mg}$ of ACPA $(2.96$ $\mu \mathrm{mol}$ ) were mixed with $1.9 \mathrm{~mL}$ of deionized water. Then, the reaction mixture was purged with inert gas for $40 \mathrm{~min}$ prior to transfer in a preheated oil bath. The polymerization was conducted for $3 \mathrm{~h}$ at 70 ${ }^{\circ} \mathrm{C}$ and then quenched by exposure to air in an ice bath. A milky dispersion was obtained, and the monomer conversion over $99 \%$ was measured by ${ }^{1} \mathrm{H}$ NMR spectroscopy. The same protocol was applied for all the copolymer nanoparticles synthesized in aqueous salt solutions. The salt concentrations were adjusted with a $5 \mathrm{M} \mathrm{NaCl}$ stock solution.

The next series of syntheses was conducted in constant volumes while varying the parameters: salt concentration, DP, and solid content. The syntheses are listed in Table S3 (entry 4-9) and Table S4 (entry 5-14). First, the stock solutions of the reactants were prepared and then targeted amounts of reagent solutions were injected into the reaction vials. The degassed vials were immersed in a preheated oil bath at $70{ }^{\circ} \mathrm{C}$. After $3 \mathrm{~h}$ reaction time, the vials were quenched in an ice bath while exposing to air. The aliquots from the dispersions were taken to determine the final conversion of DAAM by
${ }^{1} \mathrm{H}$ NMR. The dispersions were further characterized with dynamic light scattering (DLS), electrophoresis, and transmission electron microscopy (TEM) techniques.

One of the copolymer compositions was chosen to study the reaction kinetics. PVBTMAC 27 macro-CTA was chain-extended with DAAM to DP 827 in aqueous salt solutions $(1 \mathrm{M})$. In a series of several syntheses, each was stopped after a certain reaction time and the conversion was determined. The proton peaks assigned to aromatic ring around $6.7 \mathrm{ppm}$ were used as a reference.

All the characterization methods are reported in the Supporting Information.

\section{RESULTS AND DISCUSSION}

Syntheses. PVBTMAC Macro-CTA. The polycation macroCTAs were synthesized via RAFT polymerization in aqueous

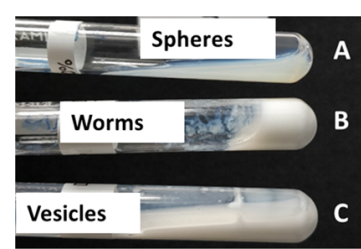

Figure 2. Photograph of dispersions of PDAAM-block-PVBTMAC ${ }_{27}$. (A) DP 250 (at $16.5 \mathrm{w} / \mathrm{w} \%, 0 \mathrm{M} \mathrm{NaCl}$ ), (B) DP 216 (at $16.9 \mathrm{w} / \mathrm{w} \%$, $1 \mathrm{M} \mathrm{NaCl}$ ), and (C) DP 413 (at $16.7 \mathrm{w} / \mathrm{w} \%, 1 \mathrm{M} \mathrm{NaCl}$ ).

solutions at $70{ }^{\circ} \mathrm{C}$ (Scheme 1). The theoretical molar masses of the macro-CTAs were obtained from the monomer conversions determined by ${ }^{1} \mathrm{H}$ NMR spectroscopy. The mean DPs and molar masses obtained with different methods are listed in Table S1. From size-exclusion chromatography (SEC), a narrow molar mass distribution was obtained $(Đ=$ 1.2) for the macro-CTA2, which confirms the controlled polymerization of VBTMAC (Figure S2). Furthermore, the final mean DPs and molar masses of the macro-CTAs were measured with NMR and UV end group analysis (see Supporting Information, Section S2). With UV spectroscopy, the molar masses of the macro-CTAs were determined using the molar extinction coefficient values obtained for CTPA 


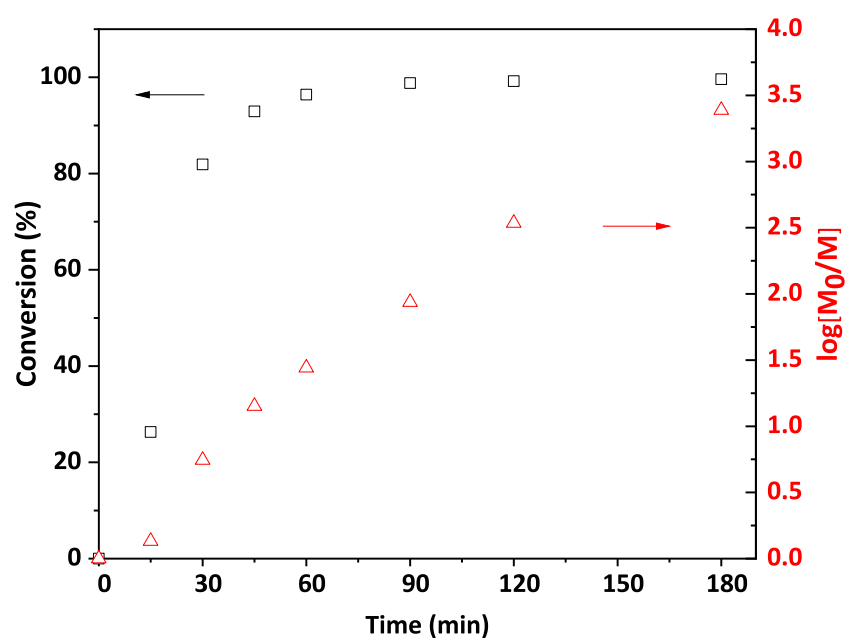

Figure 3. Conversion of DAAM (black $\square$ ) versus time and the corresponding semilogarithmic plot $(\operatorname{red} \Delta)$ for the polymerization of DAAM with PVBTMAC 27 at $70{ }^{\circ} \mathrm{C}$.

(Figure S1). The integrated intensities of the aromatic proton peaks of VBTMAC in the NMR spectra were compared with those of the methyl protons of the CTA end group (Figure 1A). From the UV analysis, higher molar masses were obtained for both macro-CTAs compared to the values obtained from NMR and the theoretical ones. It has been shown that the UV end group analysis is very sensitive to small shifts in the absorbance maxima and the scattering effect from the polymer solutions can also affect the absorbance values. ${ }^{55}$ This is why the molar masses from NMR were used in the copolymer syntheses. The macro-CTAs were named PVBTMAC ${ }_{21}$ and PVBTMAC $_{27}$ based on their molar masses 4725 and $5970 \mathrm{~g}$ $\mathrm{mol}^{-1}$ from NMR.

PVBTMAC-PDAAM Copolymers via Aqueous RAFT Dispersion Polymerization. PVBTMAC-PDAAM block copolymer nanoparticles were synthesized by the chain extension of cationic macro-CTAs with water-miscible monomer DAAM via RAFT polymerization (Scheme 1B). The first series of nanoparticles was synthesized in salt-free water, varying the target DP of PDAAM and solid content (Table S2). Then, the solvent was changed to aqueous salt solutions. In the second series, the copolymer nanoparticles were synthesized with targeting to constant DP of PDAAM while changing the $\mathrm{NaCl}$ concentration and the solid content (Table S3). The final series of syntheses was conducted in constant $\mathrm{NaCl}$ concentration, changing the other two parameters (Table S4). Monomer conversions were high (>95\%) as determined by ${ }^{1} \mathrm{HNMR}$. The theoretical molar masses of the copolymers are reported in Tables S2-S4.

In the first series, both PVBTMAC 21 and PVBTMAC $_{27}$ were used as macro-CTAs under salt-free conditions. During the polymerizations, the reaction mixtures turned from transparent to cloudy ones, indicating the in situ self-assembly of copolymers in each case. The cloudiness of the dispersions increased with either increase in the solid content or DP of PDAAM. The monomer DAAM showed poor solubility in high solids $(>28 \mathrm{w} / \mathrm{w} \%)$. The ${ }^{1} \mathrm{H}$ NMR spectrum of the copolymer obtained from the salt-free dispersions is shown in Figure $1 \mathrm{~B}$.

Polymerizations in Salt Solutions. The PVBTMAC 27 macro-CTA was chain-extended with targeting PDAAM DP $\approx 250$ in salt solutions. The $\mathrm{NaCl}$ concentrations varied from 0.3 to $2 \mathrm{M}$ in the syntheses conducted with different solid contents $(16.6-20 \%)$. In the presence of a salt ( 0.3 and 0.5 $\mathrm{M})$, the aqueous mixtures turned opaque within few min after immersing in an oil bath at $70{ }^{\circ} \mathrm{C}$. The dispersions obtained at $20 \mathrm{w} / \mathrm{w} \%$ showed the characteristics of free-standing gels with increasing the salt concentration from 0.5 to $1 \mathrm{M}$ (entries 6-8, Table S3). When further increasing the salt concentration up to $2 \mathrm{M}$, the reaction mixtures turned milky white dispersions (entries 3 and 9, Table S3).

Next, the reactions were conducted keeping $\mathrm{NaCl}$ (1 M) concentration constant. With increasing the DP of PDAAM, the reaction mixtures changed from turbid dispersions (entry 5, Table S4) to gels (entries 1 and 6, Table S4) and finally, the gel structures broke into viscous fluids or milky dispersions (entries 2, 3, 7-11, and 13, Table S4). A photograph of the dispersions with varying parameters is shown in Figure 2. The changes in the appearances of the dispersions indicated morphological changes typical in PISA. At high solids, 23 and $25 \mathrm{w} / \mathrm{w} \%$, with target DPs above 400 (entries 4 and 14, Table S4), a reverse physical change from fluid to free-standing gels occurred.

Kinetic Studies. One of the copolymer compositions was used to study the reaction kinetics. A series of several syntheses

Table 1. List of Copolymer Nanoparticles Obtained from RAFT Aqueous Dispersion Polymerization and Summary of Characterization Data

\begin{tabular}{|c|c|c|c|c|c|c|}
\hline entry & copolymer $\mathrm{V}_{\mathrm{n}}-\mathrm{D}_{\mathrm{m}}-\mathrm{m} \%-x \mathrm{M}$ & $\operatorname{size}_{\mathrm{DLS}}(\mathrm{d} \cdot \mathrm{nm})^{a}$ & zeta potential $(\mathrm{mV})^{b}$ & mobility $(\mu \mathrm{m} \mathrm{cm} / \mathrm{Vs})^{b}$ & morphology $y_{\mathrm{TEM}}$ & $\mathrm{PDI}_{\mathrm{DLS}}$ \\
\hline 1 & $\mathrm{~V}_{21}-\mathrm{D}_{68}-9.5-0 \mathrm{M}$ & 40 & 63.3 & 4.9 & spheres & 0.125 \\
\hline 2 & $\mathrm{~V}_{21}-\mathrm{D}_{151}-8.2-0 \mathrm{M}$ & 37 & 64.3 & 5.0 & spheres & 0.148 \\
\hline 3 & $\mathrm{~V}_{21}-\mathrm{D}_{206}-9.3-0 \mathrm{M}$ & 53 & 54 & 4.2 & spheres & 0.249 \\
\hline 4 & $\mathrm{~V}_{21}-\mathrm{D}_{72}-16.3-0 \mathrm{M}$ & 41 & 58.5 & 4.6 & spheres & 0.073 \\
\hline 5 & $\mathrm{~V}_{21}-\mathrm{D}_{143}-15.2-0 \mathrm{M}$ & 63 & 64.6 & 5.0 & spheres & 0.049 \\
\hline 6 & $\mathrm{~V}_{21}-\mathrm{D}_{206}-16.7-0 \mathrm{M}$ & 62 & 49.3 & 3.8 & spheres & 0.196 \\
\hline 7 & $\mathrm{~V}_{21}-\mathrm{D}_{48}-25.7-0 \mathrm{M}$ & 45 & 60.5 & 4.7 & spheres & 0.085 \\
\hline 8 & $\mathrm{~V}_{21}-\mathrm{D}_{142}-24.6-0 \mathrm{M}$ & 104 & 65.3 & 5.1 & spheres & 0.063 \\
\hline 9 & $\mathrm{~V}_{21}-\mathrm{D}_{216}-23-0 \mathrm{M}$ & 153 & 61.4 & 4.8 & spheres & 0.042 \\
\hline 10 & $\mathrm{~V}_{27}-\mathrm{D}_{250}-16.5-0 \mathrm{M}$ & 78 & & & spheres & 0.077 \\
\hline 11 & $\mathrm{~V}_{27}-\mathrm{D}_{415}-16.8-0 \mathrm{M}$ & 163 & 62 & 4.8 & spheres & 0.055 \\
\hline 12 & $\mathrm{~V}_{27}-\mathrm{D}_{335}-28.5-0 \mathrm{M}$ & 384 & 61.4 & 4.8 & spheres & 0.077 \\
\hline
\end{tabular}

${ }^{a}$ Mean hydrodynamic diameters from CONTIN at $90^{\circ}$ by DLS. ${ }^{b}$ Average zeta potentials and electrophoretic mobilities from three consecutive measurements using a Zetasizer. 

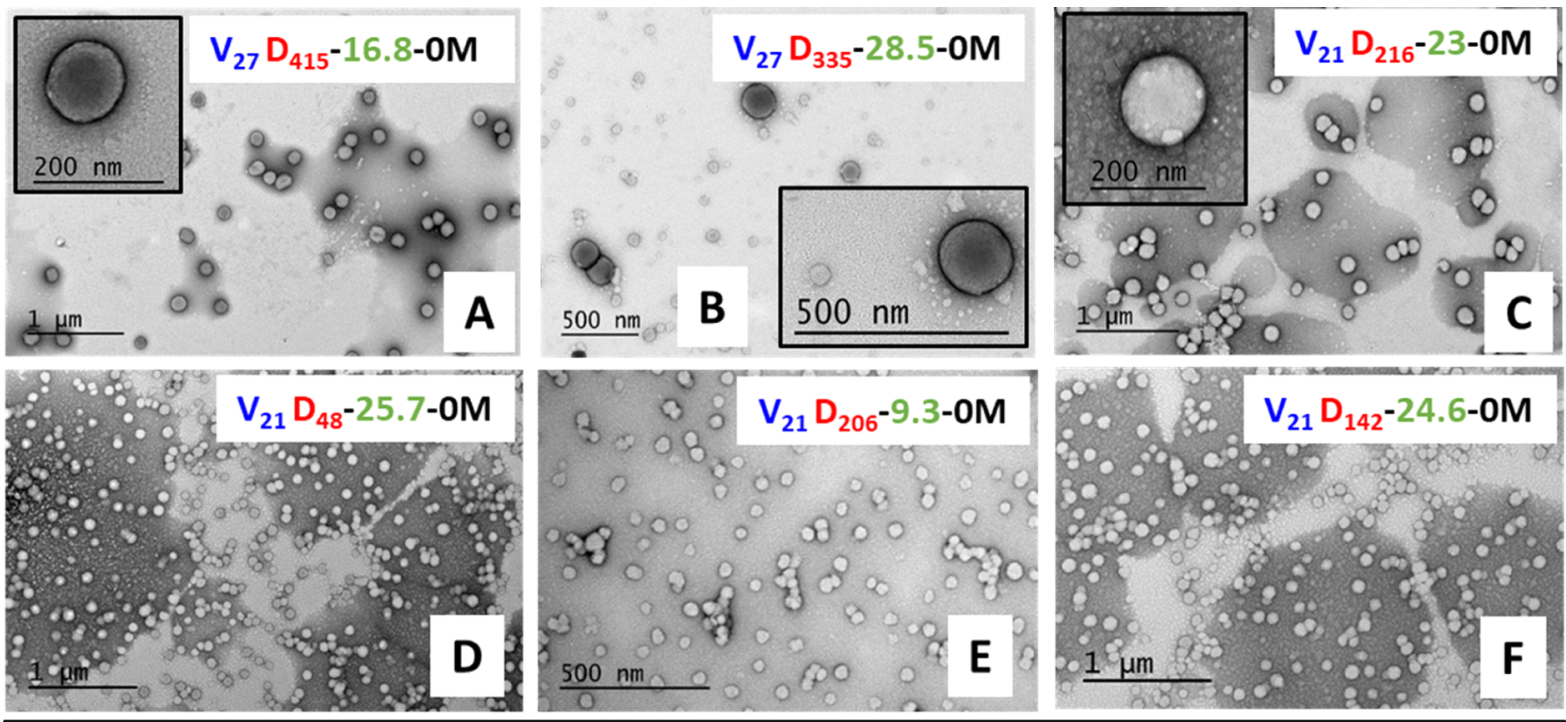

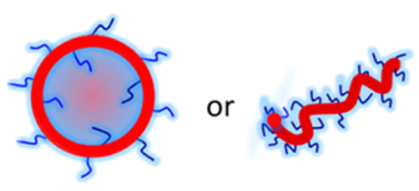

Higher-order morphologies

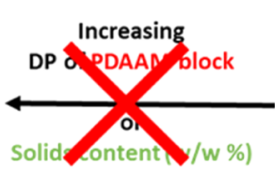

O $\mathrm{M} \mathrm{NaCl}$

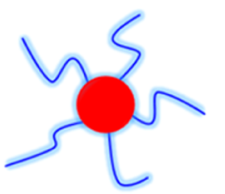

PVBTMAC-PDAAM

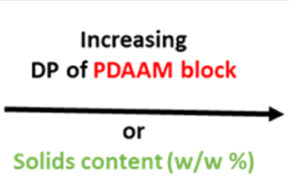

$0 \mathrm{M} \mathrm{NaCl}$

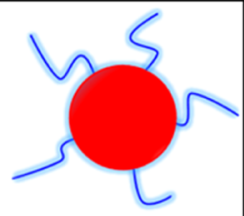

Spheres

Figure 4. TEM images of spherical nanoparticles obtained from the salt-free dispersions with varying DP of DAAM and total solids (w/w \%).

Table 2. Nanoparticles Obtained from Dispersion Polymerizations Conducted with PVBTMAC 27 in Salt Solutions at Different Solid Contents $(\mathbf{w} / \mathbf{w} \%)$

\begin{tabular}{|c|c|c|c|c|c|c|}
\hline entry & copolymer $\left(\mathrm{V}_{\mathrm{n}}-\mathrm{D}_{\mathrm{m}}-\mathrm{m} \%-x \mathrm{M}\right)$ & $\operatorname{size}_{\mathrm{DLS}}(\mathrm{d} \cdot \mathrm{nm})^{a}$ & zeta potential $(\mathrm{mV})^{b}$ & mobility $(\mu \mathrm{mcm} / \mathrm{Vs})^{b}$ & morphology (TEM) & $\mathrm{PDI}_{\mathrm{DLS}}$ \\
\hline 1 & $\mathrm{~V}_{27}-\mathrm{D}_{250}-16.6-0.3 \mathrm{M}$ & 155 & 50 & 3.9 & fused spheres & 0.035 \\
\hline 2 & $\mathrm{~V}_{27}-\mathrm{D}_{252}-16.8-0.5 \mathrm{M}$ & 113 & 45 & 3.5 & fused spheres & 0.129 \\
\hline 3 & $\mathrm{~V}_{27}-\mathrm{D}_{250}-16.6-2 \mathrm{M}$ & $565^{*}$ & 51 & 4.0 & vesicles, lamellae & 0.151 \\
\hline 4 & $\mathrm{~V}_{27}-\mathrm{D}_{248}-20-0 \mathrm{M}$ & 83 & & & spheres & 0.073 \\
\hline 5 & $\mathrm{~V}_{27}-\mathrm{D}_{248}-20-0.3 \mathrm{M}$ & 148 & & & fused spheres & 0.066 \\
\hline 6 & $\mathrm{~V}_{27}-\mathrm{D}_{248}-20-0.5 \mathrm{M}$ & $785^{*}$ & & & worms & 0.154 \\
\hline 7 & $\mathrm{~V}_{27}-\mathrm{D}_{248}-20-0.7 \mathrm{M}$ & $876^{*}$ & & & worms & 0.181 \\
\hline 8 & $\mathrm{~V}_{27}-\mathrm{D}_{248}-20-1 \mathrm{M}$ & $684^{*}$ & & & worms, lamellae & 0.271 \\
\hline 9 & $\mathrm{~V}_{27}-\mathrm{D}_{248}-20-1.5 \mathrm{M}$ & 227 & & & spheres, vesicles & 0.104 \\
\hline
\end{tabular}

${ }^{a}$ Mean hydrodynamic diameters from CONTIN at $90^{\circ}$ by DLS. ${ }^{b}$ Average zeta potentials and electrophoretic mobilities from three consecutive measurements using a Zetasizer. *Apparent values calculated for a sphere.

was conducted in aqueous salt solutions $(1 \mathrm{M})$ with the same PDAAM target DP 827 at $20 \mathrm{w} / \mathrm{w} \%$. The conversion samples were collected from the polymerizations quenched at different time intervals. Integrated intensities of the residual proton peaks of the vinyl group of DAAM were measured using PVBTMAC $_{27}$ aromatic signals $(6.45-7 \mathrm{ppm})$ as a reference. From the NMR analysis, it was clear that the full conversion of DAAM can be achieved within $1.5-3 \mathrm{~h}$ reaction time. The monomer conversions are plotted against time in Figure 3. The transparent reaction solutions turn turbid within 2 min and with further increasing the reaction time, the dispersions become milky white. Due to the in situ self-assembly of copolymers, there is an increase in local concentration of monomers within the particles. Therefore, after a short initiation period, high monomer conversions are achieved within $60 \mathrm{~min}$. The semilogarithmic plot in Figure 3 shows that the rate of polymerization increased linearly after $15 \mathrm{~min}$. This indicates that the polymerization is controlled. The kinetic results are consistent with those on nonionic copolymer systems of PDAAM. ${ }^{50,54}$

The estimation of the molar masses of the polymers was based on NMR. Several trials were made to get information from SEC, with no success, however. Methanol is a good solvent for both blocks but instead of separation, the samples were absorbed in the columns. The homo-polycation was successfully measured with water/acetonitrile as an eluent. HFIP dissolves the polymers but the separations were of very low quality, even for the polycation.

PVBTMAC-PDAAM Nanoparticles. The dispersions obtained from the polymerizations were characterized by DLS and TEM. For details, see the Supporting Information. The abbreviations used for the samples give the reaction conditions as follows. $\mathrm{V}_{\mathrm{n}}-\mathrm{D}_{\mathrm{m}}-\mathrm{m} \%-x \mathrm{M} ; \mathrm{V}_{\mathrm{n}}=$ PVBTMAC with $\mathrm{DP}_{\mathrm{NMR}}, \mathrm{D}_{\mathrm{m}}$ = PDAAM block with target DP $\mathrm{m}, \mathrm{m} \%=$ total solids $(\mathrm{w} / \mathrm{w}$ $\%)$, and $x \mathrm{M}$ is the $\mathrm{NaCl}$ concentration in the reaction mixture. 


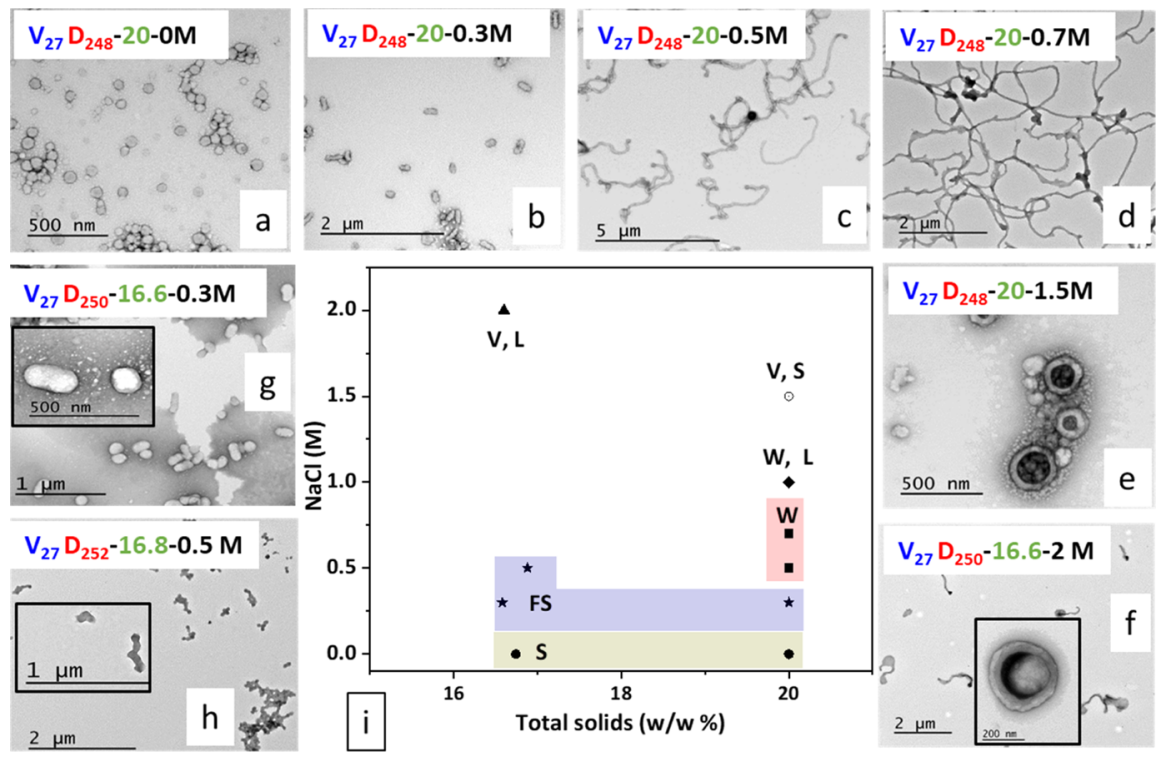

Figure 5. TEM images of nanoparticles from saline aqueous dispersions with two different solid contents, $20 \mathrm{w} / \mathrm{w} \%$ (a-e), and 16-17\% (g,h,f). In particle phase diagram (i), $\mathrm{S}=$ spheres, $\mathrm{FS}=$ fused spheres, $\mathrm{W}=$ worms, $\mathrm{L}=$ lamellae, and $\mathrm{V}=$ vesicles.

Table 3. List of Nanoparticles Obtained with Varying the Target DP of PDAAM and Solid Content at Constant Salt Concentration (1 M NaCl)

\begin{tabular}{clrll} 
entry & $\begin{array}{c}\text { copolymer } \\
\left(\mathrm{V}_{\mathrm{n}}-\mathrm{D}_{\mathrm{m}}-\mathrm{m} \%-x \mathrm{M}\right)\end{array}$ & $\begin{array}{c}\text { size }_{\mathrm{DLS}} \\
(\mathrm{d} \cdot \mathrm{nm})^{a}\end{array}$ & morphology (TEM) & PDI $_{\text {DLS }}$ \\
\hline 1 & $\mathrm{~V}_{27}-\mathrm{D}_{216}-16.9-1 \mathrm{M}$ & $778^{*}$ & Worms & 0.171 \\
2 & $\mathrm{~V}_{27}-\mathrm{D}_{413}-16.7-1 \mathrm{M}$ & $632^{*}$ & vesicles, lamellae & 0.127 \\
3 & $\mathrm{~V}_{27}-\mathrm{D}_{835}-16.4-1 \mathrm{M}$ & 584 & Vesicles & 0.012 \\
4 & $\mathrm{~V}_{27}-\mathrm{D}_{420}-23-1 \mathrm{M}$ & $1006^{*}$ & worms, lamellae & 0.218 \\
5 & $\mathrm{~V}_{27}-\mathrm{D}_{82}-20-1 \mathrm{M}$ & 90 & Spheres & 0.173 \\
6 & $\mathrm{~V}_{27}-\mathrm{D}_{165}-20-1 \mathrm{M}$ & $405^{*}$ & Worms & 0.277 \\
7 & $\mathrm{~V}_{27}-\mathrm{D}_{330}-20-1 \mathrm{M}$ & $566^{*}$ & worms, lamellae, and & 0.113 \\
& & & vesicles & \\
8 & $\mathrm{~V}_{27}-\mathrm{D}_{413}-20-1 \mathrm{M}$ & $503^{*}$ & lamellae, vesicles & 0.099 \\
9 & $\mathrm{~V}_{27}-\mathrm{D}_{496}-20-1 \mathrm{M}$ & $456^{*}$ & lamellae, vesicles & 0.155 \\
10 & $\mathrm{~V}_{27}-\mathrm{D}_{580}-20-1 \mathrm{M}$ & $475^{*}$ & lamellae, vesicles & 0.126 \\
11 & $\mathrm{~V}_{27}-\mathrm{D}_{827}-20-1 \mathrm{M}$ & 530 & Vesicles & 0.005 \\
12 & $\mathrm{~V}_{27}-\mathrm{D}_{413}-10-1 \mathrm{M}$ & 120 & Spheres & 0.002 \\
13 & $\mathrm{~V}_{27}-\mathrm{D}_{413}-15-1 \mathrm{M}$ & $424^{*}$ & vesicles, lamellae & 0.121 \\
14 & $\mathrm{~V}_{27}-\mathrm{D}_{413}-25-1 \mathrm{M}$ & $681^{*}$ & lamellae, worms & 0.099
\end{tabular}

${ }^{a}$ Mean hydrodynamic diameters from CONTIN at $90^{\circ}$ by DLS. *Apparent values calculated for a sphere.

Nanoparticles from Salt-Free Dispersions. The intensityaveraged hydrodynamic diameters measured by DLS for the dispersions $(0.1 \mathrm{w} / \mathrm{w} \%)$ are shown in Table 1 . As is typical in PISA reactions, the copolymers self-assembled to various nanostructures in situ while increasing the length of the coreforming block. The hydrodynamic diameters of the nanoparticles increased in each case with the increase in the DP of the PDAAM block at different solid contents. The intensityaveraged size distributions are shown in Figure S3. The distributions seemed to get narrower with the increase in the solid content. The zeta potentials show that the nanoparticles are stabilized by positively charged shells. The electrophoretic mobilities and zeta potentials of the particles varied without any clear tendency (Table1).

TEM analysis shows that only spherical nanoparticles are obtained in salt-free reaction mixtures (Figures 4 and S4).
When using polyelectrolyte stabilizers in PISA polymerizations, only kinetically trapped spheres have been observed. ${ }^{33,43}$ With increasing solid content or DP of PDAAM, the diameters of the particles increased but no morphological changes occurred. Because of electrostatic repulsion, no fusion of the spheres took place. Similar diblock copolymer systems have been reported earlier, where polyelectrolyte stabilizer chains were extended with DAAM or hydroxypropyl methacrylate. As in the present case, under salt-free conditions, only an increase in the spheres was observed. ${ }^{34,43-45}$

Two macro-CTAs with nearly similar DPs (21 and 27) were tested, and it is worth noting that the small difference in the DP did not affect the particle morphologies. In the following, we will discuss only the cases where PVBTMAC 27 was used. When the target DP of PDAAM was increased from 250 to 415 , the particle diameters almost doubled while the distributions remained very narrow (entry 11 in Table 1, Figures $4 \mathrm{~A}-\mathrm{F}$ and $\mathrm{S} 3$ ). In the sample with the highest solid content, sample 12 in Table 1, bimodal size distributions were observed by both DLS and TEM (see also Figures 4B and S3). Obviously, the electrostatic repulsion is getting too high under these conditions.

In PISA, morphological transitions in the self-assembled structures can occur either by fusion of spheres or exchange of the copolymer chains within the neighbor aggregates. The final morphologies can be altered by changing the packing parameter by either increasing the hydrophobic block length or solid content. In nanoparticles stabilized by charged chains, the morphological transitions are more complicated than those in nonionic systems. In previous investigations, ${ }^{33,38,43,44}$ the higher-order morphologies were achieved by incorporating nonionic repeating units. Another strategy used to decrease the repulsion was the use of a mixture of charged and noncharged stabilizers. ${ }^{44}$ The final morphologies of the particles have also been observed to depend on the ionic strength or $\mathrm{pH}^{31,38}$ Therefore, we used $\mathrm{NaCl}$ to screen the electrostatic repulsions in the shell region and thus to promote the higher-order morphologies. The dispersions obtained from the polymerizations conducted in the presence of $\mathrm{NaCl}$ are listed in Table 2. 


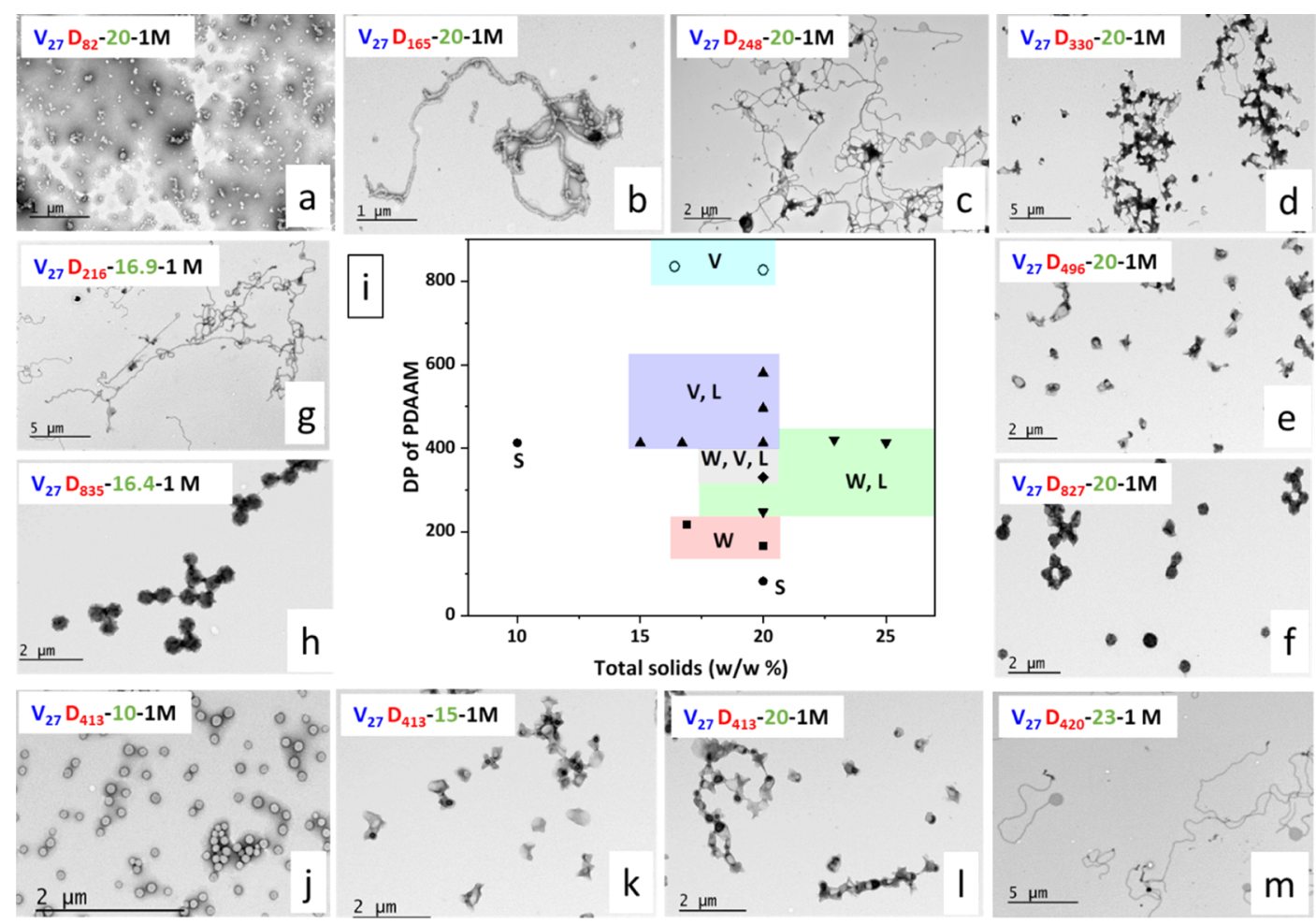

Figure 6. TEM micrographs of nano-objects obtained in the presence of $\mathrm{NaCl}(1 \mathrm{M})$ with different target DP of PDAAM and solids. (a-f) Target DP increases from 82 to 827 at $20 \mathrm{w} / \mathrm{w} \%$; (g,h) target DP 216 and 835 at low solids w/w \%; (j-m) different solid contents w/w \%; and (i) phase diagram of particles.

Morphologies in the Presence of a Salt. Particle sizes increased with the addition of salt in the polymerizations. The size distributions of the particles obtained at low solid content are shown in Figure S5. With the increase in the salt concentration up to $2 \mathrm{M}$, the diameters of the particles increased drastically (entries $1-3$ in Table 2). With TEM, we see the morphological changes induced by the increasing salt concentration, while the target DP and solid content are kept constant. With 0.3 or $0.5 \mathrm{M}$ salt, fused spheres were obtained. Polymerization in $2 \mathrm{M} \mathrm{NaCl}$ leads to the formation of vesicles and lamellar structures (Figure $5 \mathrm{f}-\mathrm{h}$ ). It was expected that following the zeta potentials (and electrophoretic mobilities) of the nanostructures would shed more light on the mechanisms of the evolvement of various morphologies. However, the small differences between the samples are more or less random.

As is seen in Figure 5a-e, the whole range of morphologies was obtained in dispersions with constant solid content $(20 \mathrm{w} /$ $\mathrm{w} \%$ ) and DP of PDAAM (248), see also Table 2, rows 4-9. With increase in $\mathrm{NaCl}$ concentration, the particle morphologies changed from spheres to fused spheres to worms to lamellae or vesicles. The addition of $0.3 \mathrm{M}$ salt (Figure $5 \mathrm{~b}$ ) leads to the formation of fused spheres. Figure $5 \mathrm{c}$ shows mixtures of worms with different structures obtained at $0.5 \mathrm{M}$ $\mathrm{NaCl}$. In TEM, elongated linear worm micelles with sphere heads can be seen, as well as branched worms with either two or three branches (see an enlarged micrograph in Figure S6). In the case of worm or lamellar structures, the particle size data from DLS are naturally not correct but are shown because it gives the order of magnitude of the structures. Upon increasing the salt concentration to $0.7 \mathrm{M}$, a few micrometers long worms with a diameter of $56 \mathrm{~nm}$ appeared (Figure $5 \mathrm{~d}$ ). The diameter is of the same order of magnitude as the diameters of spherical particles obtained in salt-free systems $(70 \mathrm{~nm}$, measured from the TEM image). This behavior resembles the self-assembling of small surfactant molecules in salt solutions. At $1.5 \mathrm{M}$ salt concentration, the repulsive interactions in corona are expected to be very much suppressed. Therefore, vesicle structures start to build up of the copolymer $\mathrm{V}_{27}-\mathrm{D}_{248}$ (Figure $5 e$ ). Besides the vesicles, a high number of spherical particles were also found in the dispersions in high $\mathrm{NaCl}$ concentrations.

The observations are very much in line with previous research by others ${ }^{12,29,38,43}$ on polyelectrolyte-stabilized PISA systems. In several cases, the charge density in the particle shells was reduced using either a mixture of charged and noncharged stabilizers ${ }^{33,44}$ and/or adding a cosolvent or changing $\mathrm{pH}^{34,39}$ In the present case, the addition of salt to the reaction mixture is enough to decrease the charge density in the macro-CTAs and to make the particle shells shrink. This promotes the $1 \mathrm{D}$ fusion of the particles. With increasing the salt concentration, the repulsive interactions decrease. The aggregation number increases with a decrease in the surface area per chain, which allows further changes in the morphology of the particles. Worm-like structures are promoted via radial elongation of the core even without increasing the PDAAM block length or solid content. Hydrophobicity of the surfaces increases and this favors such collisions of the entities, which lead to either branching or long fiber-like worm structures. In high salt regimes, the polymers start to behave as noncharged ones, and to minimize the surface energy, the hydrophobic cores force the entities into lamellar or vesicular structures. The progress of the morphologies follows well the theoretical predictions by Borisov and Zhulina. ${ }^{10}$

Effect of DP of PDAAM Block and Solid Content ( $w / w \%)$. To systematically study the effect of the essential parameters, 

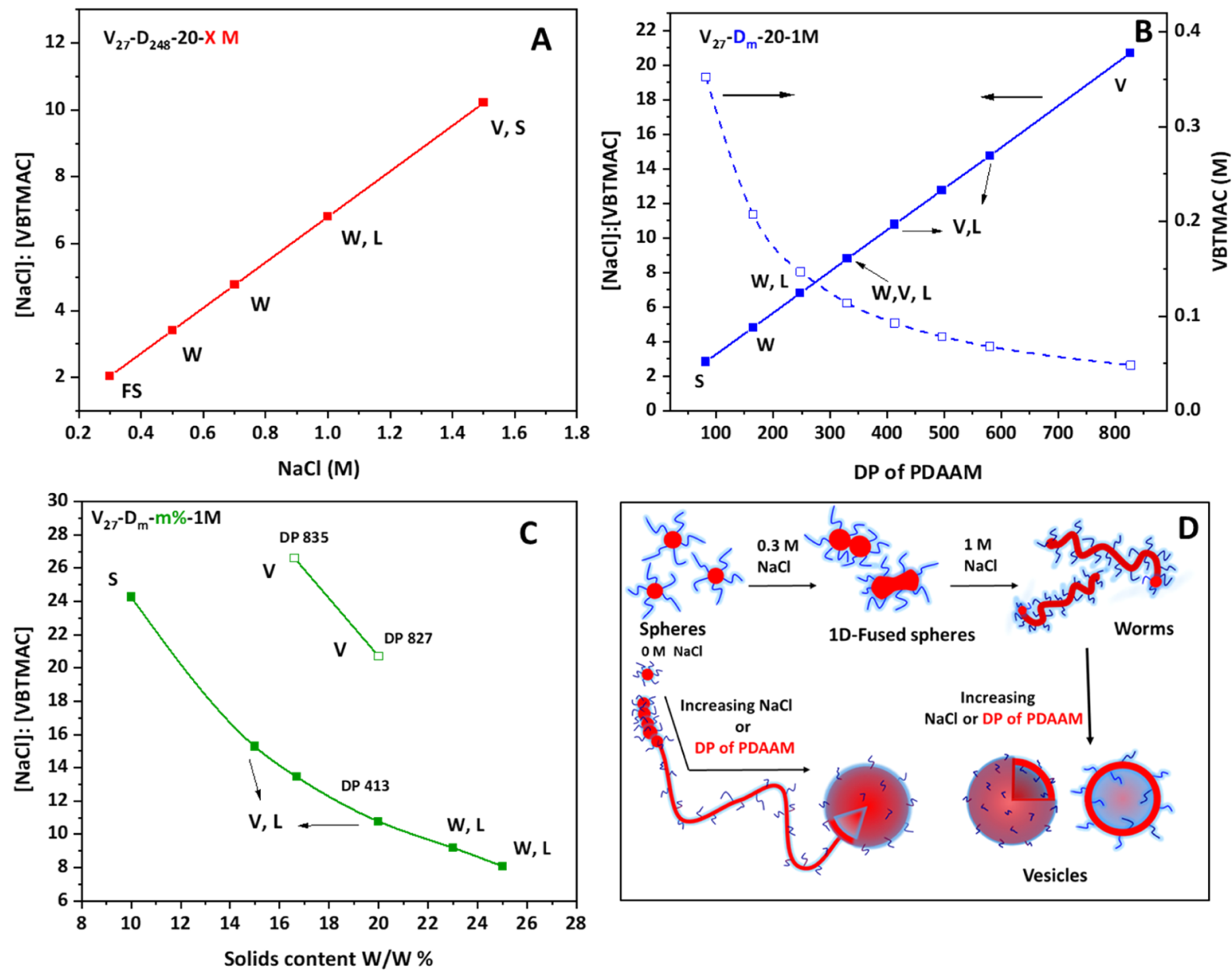

Figure 7. Particle morphology versus ionic strength with changing the parameters (A) $\mathrm{NaCl}$ (B) DP of PDAAM, and (C) solid content (w/w \%). (D) Corresponding illustration of salt-induced morphological transition.

DP of PDAAM and total solid content, several syntheses were conducted by keeping the salt concentration constant. The particles obtained from these syntheses are listed in Table 3, together with DLS and TEM data.

As was shown above, at high salt regimes, the polycation macro-CTA can act as a nonionic stabilizer. At low target DP 82 , only spherical particles were formed at $20 \%$ solids (Figure 6a). However, when the target DP of PDAAM was doubled to 165 , worm-like micelles with different lengths were obtained at $20 \%$ solids (Figure 6b). A long entangled worm phase was observed at DP 216 in low solid contents, see Figure 6g. Further increasing the DP of the second block, the charge repulsions are further reduced in the coronas upon the radial elongation of the hydrophobic cores. Thus, with PDAAM target DP 248 and 330, mixtures of worms and lamellae and/or vesicles were obtained (Figure 6c,d).

The morphological transitions from worms to bilayer structures were attained with further increase in the DP of DAAM. However, the $\mathrm{V}_{27}-\mathrm{D}_{\mathrm{m}}$ copolymers formed mixtures of vesicles and lamellae or interconnected vesicles with lamellae in the target DP range from 413 to 580 (see Figures 6e and 1, S7a,b). An et al. reported PISA of PDAAM copolymers, where a nonionic stabilizer was chain-extended with DAAM. The mixed phase of lamellae and vesicles was prone to form in high solid content $(25 \% \mathrm{w} / \mathrm{v})$, whereas at low solid contents, pure lamellae phase was observed. ${ }^{56}$ The interconnected vesicle phases are similar to those in polystyrene copolymer systems with either nonionic PEG or ionic PAA stabilizers. ${ }^{57,58}$ At high target PDAAM DP > 800 in both 16.4 and $20 \%$ solid contents, large nonuniform vesicles were observed under TEM (see Figure $6 \mathrm{~h}, \mathrm{f}$ ). The topologies of the vesicles are similar to the large compound vesicles obtained from PS-PEO copolymer particles. ${ }^{58}$ For clarity, the vesicles obtained from the samples 11 and 3 (Table 3) were further characterized with other imaging techniques cryo-TEM and FESEM (see Figure S8). Imaged with FESEM in the dry state, the vesicles looked like dense raisins, and with cryo-TEM, similar morphologies were observed as in TEM. The TEM images of individual nanoparticles from this series are shown in Figure S7d.

The particles synthesized varying the solid content and targeting a constant DP 413 are shown in Figure $6 j-m$. Regardless of salt concentration, only spherical particles were obtained at $10 \%$ (Figure 6j). The spheres are narrowly dispersed with a diameter of $120 \mathrm{~nm}$. Increasing the solid content to 15 and $20 \mathrm{w} / \mathrm{w} \%$ leads to a transition from spheres to mixtures of lamellae and vesicles. At $15 \%$, the copolymers profoundly favored lamellar structures. A further increase to 23 and $25(\mathrm{w} / \mathrm{w} \%)$ leads to mixtures of worms and lamellae connected with worm structures (Figures $6 \mathrm{~m}$ and S7C). These morphological changes at high solids are somewhat different from a previous report where a zwitterionic stabilizer chain was extended with HPMA with DP $\approx 400 .^{20}$

Figure 7 summarizes the observations. In Figure 7A, one can see how the morphologies change from spheres to worms, 

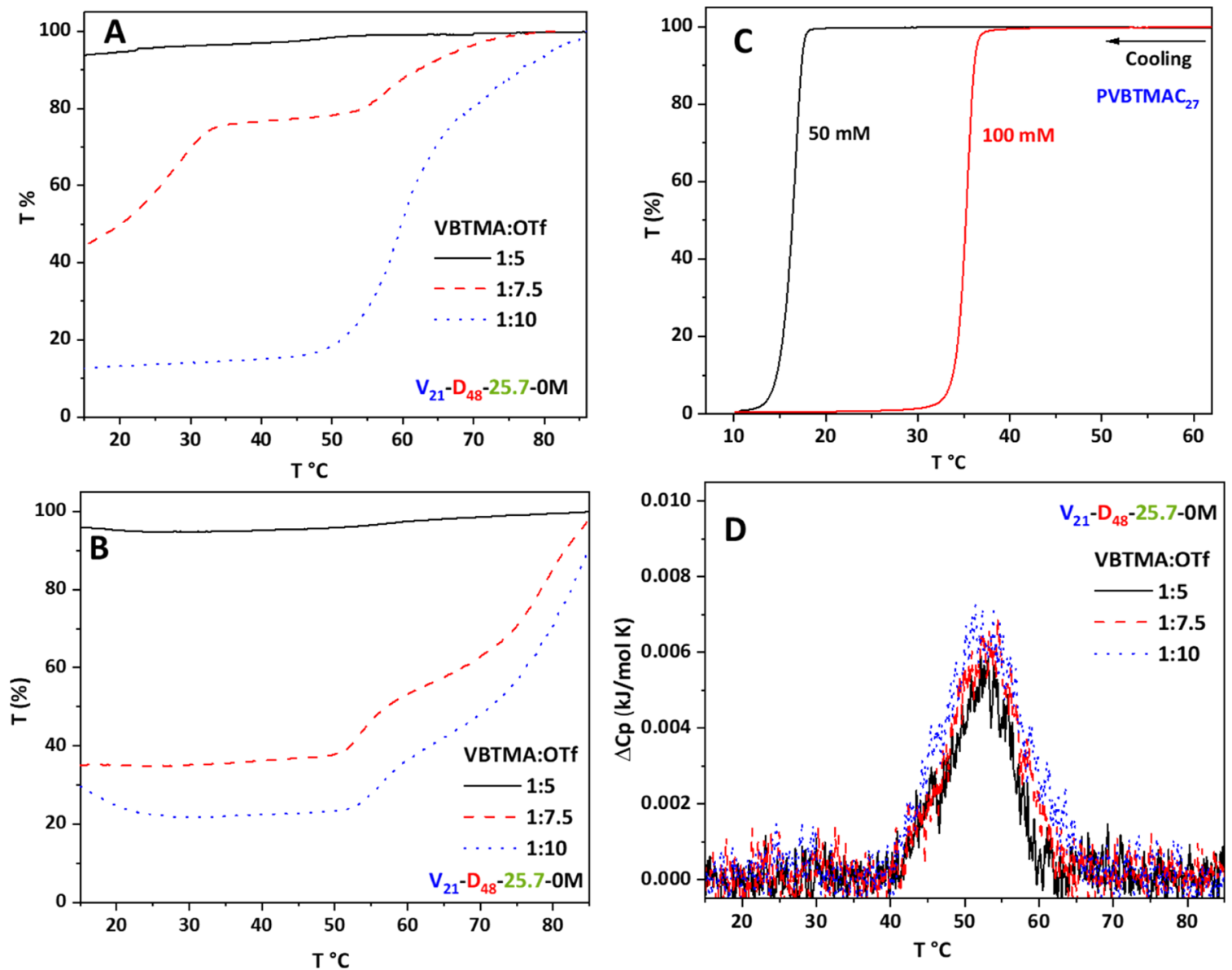

Figure 8. Particles synthesized in salt-free solutions. (A) Normalized transmittance cooling curves for spherical nanoparticles of $\mathrm{V}_{21}-\mathrm{D}_{48}(0.1 \mathrm{w} / \mathrm{w}$ $\%)$ in aqueous triflate solutions with different cation/anion ratios. (B) Corresponding heating curves. (C) Transmittance cooling curves for PVBTMAC $_{27}(1 \mathrm{mg} / \mathrm{mL})$ in aqueous triflate solutions (LiOTf concentrations are next to the lines). (D) Endotherms obtained for spherical nanoparticles of $\mathrm{V}_{21}-\mathrm{D}_{48}(0.1 \mathrm{w} / \mathrm{w} \%)$ with different cation/anion ratios. Heating rate $1{ }^{\circ} \mathrm{C} / \mathrm{min}$.
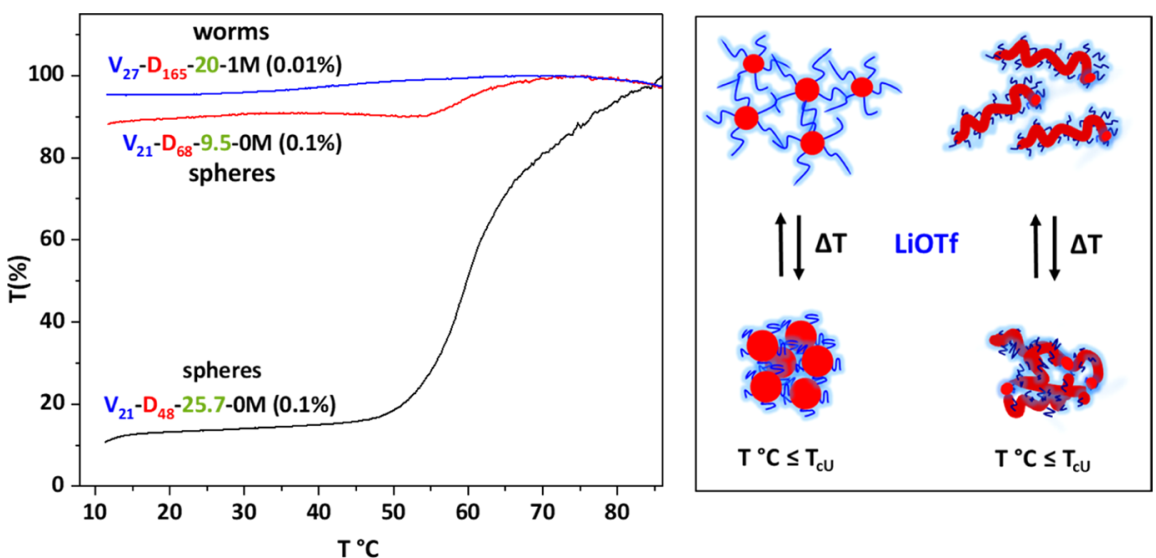

Figure 9. Thermoresponsive behavior of nanoparticles with different morphologies in aqueous triflate solutions with a cation/anion ratio of 1:10 (left). The solid content is indicated in parentheses next to the sample code. $T_{\mathrm{cU}}=$ cloud point temperature.

lamellae, and vesicles with increasing salt concentration. A similar change is observed in Figure $7 \mathrm{~B}$ with the increase in the DP of PDAAM. Finally, Figure $7 \mathrm{C}$ shows how the morphologies evolve with increasing solid content. The salt concentration is crucial; when the salt/cation ratio is below 3, mainly spheres exist, and with the ratio 10 or above, only lamellae and/or vesicles are found (Figure 7A,B). Between these extremes, the entities are mainly worms.
Thermoresponsive Behavior in Triflate Solutions. As we have shown earlier, it is possible to modulate thermal behavior of PVBTMAC with hydrophobic counterions. In the presence of triflate ions (OTf), the aqueous polymer phase-separates at temperatures below UCST. ${ }^{48}$ Correspondingly, OTf turn the polycation-stabilized nanoparticles thermoresponsive. The addition of OTf increases the cloudiness of the dispersions, thus indicating the aggregation of the particles. The trans- 
mittances of dispersion of spheres synthesized in salt-free solutions change interestingly while cooling the samples. When adding five equivalents of OTf per cationic unit, the cloudiness of the dispersions increased. Normalized transmittance curves for dispersions of $\mathrm{V}_{21}-\mathrm{D}_{48}$ (Table 1, sample 7), measured in different OTf concentrations (5, 7.5, and 10 equivalents), are shown in Figures $8 \mathrm{~A}, \mathrm{~B}$. Upon cooling, the particles start to phase-separate around $65{ }^{\circ} \mathrm{C}$. The process is reversible with heating. Comparing to homopolymers PVBTMAC (Figure $8 \mathrm{C})$, the cloud points of the polycation stabilizers are shifted to high temperatures in the presence of OTf (10 or 20 equivalents). The phase separation is difficult to be studied with DSC owing to the very low content of the polycation. A very weak endotherm can be observed during heating, however (Figure 8D). The transmittance curves are different for polymers with different compositions, see Figure S9.

The observation that the transition under certain conditions takes place in two steps is important. It may be assumed that the segments of the polycation close to the hydrophobic core collapse first, and the outer parts of the chains contract later, at lower temperature. An observation which serves indirect support for this assumption is that during repeated coolingheating cycles, two steps are observed only during the first cooling. This suggests that after the first contraction, some polymer segments remain collapsed and thus, later, only one transition is observed. The finding is of general interest because it is analogous to the behavior of PNIPAM chains bound to surfaces. We have observed that the chains bound to gold nanoparticles show two clear transition steps upon heating, the segments close to the surface collapse first and those further out follow afterward. ${ }^{59}$ The two transitions have recently been discussed also by Winnik et al. ${ }^{60}$

Particles with different morphologies were obtained in saline systems. They all show the thermal collapse of the polycation when triflate has been added. In Figure 9, it is seen that in the case of a sphere with a small core, the change in transmittance is huge. The magnitude of the transmittance changes with the particle morphology. In the figure, the cation/anion ratio is 1:10 in all samples, but sample concentrations vary because due to the strong scattering, the dispersions needed to be diluted in different ratios. However, the more the samples contain the stabilizer, the greater is the change.

\section{CONCLUSIONS}

Polyelectrolyte-stabilized copolymer nanoparticles have been synthesized via RAFT aqueous dispersion polymerization. A cationic macro-CTA, PVBTMAC, was chain-extended with DAAM to create self-assembled core-shell nanoparticles. Due to the electrostatic repulsion, only kinetically trapped spherical particles were obtained in salt-free dispersions. Using a simple salt $\mathrm{NaCl}$, morphological transitions from spheres to fused spheres, worms, lamellae, and vesicles became possible. Worms and lamellae or vesicles could also be prepared by varying the DP of PDAAM or the solid content in the formulations in $1 \mathrm{M}$ aqueous $\mathrm{NaCl}$. The experiments show that PVBTMAC is a versatile cationic stabilizer; the whole spectrum of morphologies can be obtained by adding salt. No dilution of cationic charges with noncharged comonomers or polymers is needed. When adding hydrophobic triflate counterions, the polycation blocks turn thermoresponsive with UCST behavior. Interestingly, with certain triflate concentrations, the phase separation taking place upon cooling occurs in two steps. Two-step transitions have earlier been observed with aqueous LCST polymers with reduced mobilities. It remains to be seen if we can substitute the chloride ion with triflate in the polymerization reactions; one may expect that much less negative ions would be needed in that case to control the particle morphologies.

\section{ASSOCIATED CONTENT}

\section{Supporting Information}

The Supporting Information is available free of charge at https://pubs.acs.org/doi/10.1021/acs.macromol.0c02771.

Characterization methods, molar mass determination of macro-CTAs, list of the syntheses of copolymer nanoparticles, characterization of copolymer particles, DLS size distributions, cryo-TEM and FESEM images of nanoparticles, transmittance curves, and micro-DSC endotherms (PDF)

\section{AUTHOR INFORMATION}

\section{Corresponding Author}

Heikki Tenhu - Department of Chemistry, University of Helsinki, Helsinki 00014, Finland; 이이.org/0000-00015957-4541; Email: heikki.tenhu@helsinki.fi

\section{Authors}

Vikram Baddam - Department of Chemistry, University of Helsinki, Helsinki 00014, Finland; @ orcid.org/0000-00015327-9066

Lauri Välinen - Department of Chemistry, University of Helsinki, Helsinki 00014, Finland

Complete contact information is available at: https://pubs.acs.org/10.1021/acs.macromol.0c02771

\section{Notes}

The authors declare no competing financial interest.

\section{ACKNOWLEDGMENTS}

We thank Electron Microscopy Unit of the Institute of Biotechnology, University of Helsinki, for providing laboratory facilities. We also thank Benita Löflund and Pasi Laurinmäki (University of Helsinki) for technical assistance in cryo-TEM. The facilities and expertise of the HiLIFE CryoEM unit at the University of Helsinki, a member of Instruct-ERIC Centre Finland, FINStruct, and Biocenter Finland are gratefully acknowledged. We also thank Dr. Marianna Kemell for FESEM images. V.B. thanks Magnus Ehrnrooth Foundation for the research grant.

\section{REFERENCES}

(1) Israelachvili, J. N.; Mitchell, D. J.; Ninham, B. W. Theory of SelfAssembly of Lipid Bilayers and Vesicles. Biochim. Biophys. Acta, Biomembr. 1977, 470, 185-201.

(2) Zhulina, E. B.; Borisov, O. V. Theory of Block Polymer Micelles: Recent Advances and Current Challenges. Macromolecules 2012, 45, 4429-4440.

(3) Astafieva, I.; Zhong, X. F.; Eisenberg, A. Critical Micellization Phenomena in Block Polyelectrolyte Solutions. Macromolecules 1993, 26, 7339-7352.

(4) Mai, Y.; Eisenberg, A. Self-Assembly of Block Copolymers. Chem. Soc. Rev. 2012, 41, 5969.

(5) Blanazs, A.; Armes, S. P.; Ryan, A. J. Self-Assembled Block Copolymer Aggregates: From Micelles to Vesicles and Their Biological Applications. Macromol. Rapid Commun. 2009, 30, 267277. 
(6) Moffitt, M.; Khougaz, K.; Eisenberg, A. Micellization of Ionic Block Copolymers. Acc. Chem. Res. 1996, 29, 95-102.

(7) Lysenko, E. A.; Bronich, T. K.; Slonkina, E. V.; Eisenberg, A.; Kabanov, V. A.; Kabanov, A. V. Block Ionomer Complexes with Polystyrene Core-Forming Block in Selective Solvents of Various Polarities. 1. Solution Behavior and Self-Assembly in Aqueous Media. Macromolecules 2002, 35, 6351-6361.

(8) Zhang, L.; Barlow, R. J.; Eisenberg, A. Scaling Relations and Coronal Dimensions in Aqueous Block Polyelectrolyte Micelles. Macromolecules 1995, 28, 6055-6066.

(9) Gao, Z.; Varshney, S. K.; Wong, S.; Eisenberg, A. Block Copolymer "Crew-Cut" Micelles in Water. Macromolecules 1994, 27, $7923-7927$.

(10) Borisov, O. V.; Zhulina, E. B. Morphology of Micelles Formed by Diblock Copolymer with a Polyelectrolyte Block. Macromolecules 2003, 36, 10029-10036.

(11) Zhang, L.; Eisenberg, A. Multiple Morphologies and Characteristics of "crew-Cut" Micelle-like Aggregates of Polystyrene-b-Poly(Acrylic Acid) Diblock Copolymers in Aqueous Solutions. J. Am. Chem. Soc. 1996, 118, 3168-3181.

(12) Zhang, L.; Eisenberg, A. Morphogenic Effect of Added Ions on Crew-Cut Aggregates of Polystyrene-b-Poly(Acrylic Acid) Block Copolymers in Solutions. Macromolecules 1996, 29, 8805-8815.

(13) Rieger, J.; Stoffelbach, F.; Bui, C.; Alaimo, D.; Jérôme, C.; Charleux, B. Amphiphilic Poly(Ethylene Oxide) Macromolecular RAFT Agent as a Stabilizer and Control Agent in Ab Initio Batch Emulsion Polymerization. Macromolecules 2008, 41, 4065-4068.

(14) Zhang, W.; D’Agosto, F.; Boyron, O.; Rieger, J.; Charleux, B. One-Pot Synthesis of Poly(Methacrylic Acid-Co-Poly(Ethylene Oxide) Methyl Ether Methacrylate)-b-Polystyrene Amphiphilic Block Copolymers and Their Self-Assemblies in Water via RAFTMediated Radical Emulsion Polymerization. A Kinetic Study. Macromolecules 2011, 44, 7584-7593.

(15) Zhang, X.; Boissé, S.; Zhang, W.; Beaunier, P.; D’Agosto, F.; Rieger, J.; Charleux, B. Well-Defined Amphiphilic Block Copolymers and Nano-objects Formedin Situvia RAFT-Mediated Aqueous Emulsion Polymerization. Macromolecules 2011, 44, 4149-4158.

(16) Li, Y.; Armes, S. P. RAFT Synthesis of Sterically Stabilized Methacrylic Nanolatexes and Vesicles by Aqueous Dispersion Polymerization. Angew. Chem., Int. Ed. 2010, 49, 4042-4046.

(17) Sugihara, S.; Armes, S. P.; Lewis, A. L. One-Pot Synthesis of Biomimetic Shell Cross-Linked Micelles and Nanocages by ATRP in Alcohol/Water Mixtures. Angew. Chem., Int. Ed. 2010, 49, 35003503.

(18) Ferguson, C. J.; Hughes, R. J.; Nguyen, D.; Pham, B. T. T.; Gilbert, R. G.; Serelis, A. K.; Such, C. H.; Hawkett, B. S. Ab Initio Emulsion Polymerization by RAFT-Controlled Self-Assembly. Macromolecules 2005, 38, 2191-2204.

(19) Delaittre, G.; Dire, C.; Rieger, J.; Putaux, J.-L.; Charleux, B. Formation of Polymer Vesicles by Simultaneous Chain Growth and Self-Assembly of Amphiphilic Block Copolymers. Chem. Commun. 2009, 20, 2887-2889.

(20) Sugihara, S.; Blanazs, A.; Armes, S. P.; Ryan, A. J.; Lewis, A. L. Aqueous Dispersion Polymerization: A New Paradigm for in Situ Block Copolymer Self-Assembly in Concentrated Solution. J. Am. Chem. Soc. 2011, 133, 15707-15713.

(21) Canning, S. L.; Smith, G. N.; Armes, S. P. A Critical Appraisal of RAFT-Mediated Polymerization-Induced Self-Assembly. Macromolecules 2016, 49, 1985-2001.

(22) Charleux, B.; Delaittre, G.; Rieger, J.; D’Agosto, F. Polymerization-Induced Self-Assembly: From Soluble Macromolecules to Block Copolymer Nano-Objects in One Step. Macromolecules 2012, 45, 6753-6765.

(23) Wan, W.-M.; Hong, C.-Y.; Pan, C.-Y. One-Pot Synthesis of Nanomaterials via RAFT Polymerization Induced Self-Assembly and Morphology Transition. Chem. Commun. 2009, 39, 5883-5885.

(24) Warren, N. J.; Armes, S. P. Polymerization-Induced SelfAssembly of Block Copolymer Nano-Objects via RAFT Aqueous
Dispersion Polymerization. J. Am. Chem. Soc. 2014, 136, 1017410185.

(25) Penfold, N. J. W.; Yeow, J.; Boyer, C.; Armes, S. P. Emerging Trends in Polymerization-Induced Self-Assembly. ACS Macro Lett. 2019, 8, 1029-1054.

(26) Khor, S. Y.; Truong, N. P.; Quinn, J. F.; Whittaker, M. R.; Davis, T. P. Polymerization-Induced Self-Assembly: The Effect of End Group and Initiator Concentration on Morphology of Nanoparticles Prepared via RAFT Aqueous Emulsion Polymerization. ACS Macro Lett. 2017, 6, 1013-1019.

(27) Zhang, X.; Rieger, J.; Charleux, B. Effect of the Solvent Composition on the Morphology of Nano-Objects Synthesized via RAFT Polymerization of Benzyl Methacrylate in Dispersed Systems. Polym. Chem. 2012, 3, 1502-1509.

(28) Blanazs, A.; Ryan, A. J.; Armes, S. P. Predictive Phase Diagrams for RAFT Aqueous Dispersion Polymerization: Effect of Block Copolymer Composition, Molecular Weight, and Copolymer Concentration. Macromolecules 2012, 45, 5099-5107.

(29) Blanazs, A.; Madsen, J.; Battaglia, G.; Ryan, A. J.; Armes, S. P. Mechanistic Insights for Block Copolymer Morphologies: How Do Worms Form Vesicles? J. Am. Chem. Soc. 2011, 133, 16581-16587.

(30) Derry, M. J.; Fielding, L. A.; Armes, S. P. PolymerizationInduced Self-Assembly of Block Copolymer Nanoparticles via RAFT Non-Aqueous Dispersion Polymerization. Prog. Polym. Sci. 2016, 52, $1-18$.

(31) Boissé, S.; Rieger, J.; Pembouong, G.; Beaunier, P.; Charleux, B. Influence of the Stirring Speed and $\mathrm{CaCl} 2$ Concentration on the Nano-Object Morphologies Obtained via RAFT-Mediated Aqueous Emulsion Polymerization in the Presence of a Water-Soluble MacroRAFT Agent. J. Polym. Sci., Part A: Polym. Chem. 2011, 49, 3346-3354.

(32) Zhang, W.; D’Agosto, F.; Boyron, O.; Rieger, J.; Charleux, B. Toward a Better Understanding of the Parameters That Lead to the Formation of Nonspherical Polystyrene Particles via RAFT-Mediated One-Pot Aqueous Emulsion Polymerization. Macromolecules 2012, 45, 4075-4084.

(33) Semsarilar, M.; Ladmiral, V.; Blanazs, A.; Armes, S. P. Anionic Polyelectrolyte-Stabilized Nanoparticles via RAFT Aqueous Dispersion Polymerization. Langmuir 2012, 28, 914-922.

(34) Williams, M.; Penfold, N. J. W.; Armes, S. P. Cationic and Reactive Primary Amine-Stabilised Nanoparticles via RAFT Aqueous Dispersion Polymerisation. Polym. Chem. 2016, 7, 384-393.

(35) North, S. M.; Armes, S. P. Aqueous Solution Behavior of Stimulus-Responsive Poly(Methacrylic Acid)-Poly(2-Hydroxypropyl Methacrylate) Diblock Copolymer Nanoparticles. Polym. Chem. 2020, $11,2147-2156$.

(36) Ning, Y.; Fielding, L. A.; Ratcliffe, L. P. D.; Wang, Y.-W.; Meldrum, F. C.; Armes, S. P. Occlusion of Sulfate-Based Diblock Copolymer Nanoparticles within Calcite: Effect of Varying the Surface Density of Anionic Stabilizer Chains. J. Am. Chem. Soc. 2016, 138, 11734-11742.

(37) Canning, S. L.; Neal, T. J.; Armes, S. P. PH-Responsive Schizophrenic Diblock Copolymers Prepared by PolymerizationInduced Self-Assembly. Macromolecules 2017, 50, 6108-6116.

(38) Boissé, S.; Rieger, J.; Belal, K.; Di-Cicco, A.; Beaunier, P.; Li, M.-H.; Charleux, B. Amphiphilic Block Copolymer Nano-Fibers via RAFT-Mediated Polymerization in Aqueous Dispersed System. Chem. Commun. 2010, 46, 1950-1952.

(39) Zhou, D.; Dong, S.; Kuchel, R. P.; Perrier, S.; Zetterlund, P. B. Polymerization Induced Self-Assembly: Tuning of Morphology Using Ionic Strength and PH. Polym. Chem. 2017, 8, 3082-3089.

(40) Semsarilar, M.; Penfold, N. J. W.; Jones, E. R.; Armes, S. P. Semi-Crystalline Diblock Copolymer Nano-Objects Prepared via RAFT Alcoholic Dispersion Polymerization of Stearyl Methacrylate. Polym. Chem. 2015, 6, 1751-1757.

(41) Lowe, A. B. RAFT Alcoholic Dispersion Polymerization with Polymerization-Induced Self-Assembly. Polymer 2016, 106, 161-181.

(42) Li, D.; Huo, M.; Liu, L.; Zeng, M.; Chen, X.; Wang, X.; Yuan, J. Overcoming Kinetic Trapping for Morphology Evolution during 
Polymerization-Induced Self-Assembly. Macromol. Rapid Commun. 2019, 40, 1900202.

(43) Semsarilar, M.; Ladmiral, V.; Blanazs, A.; Armes, S. P. Cationic Polyelectrolyte-Stabilized Nanoparticles via RAFT Aqueous Dispersion Polymerization. Langmuir 2013, 29, 7416-7424.

(44) Williams, M.; Penfold, N. J. W.; Lovett, J. R.; Warren, N. J.; Douglas, C. W. I.; Doroshenko, N.; Verstraete, P.; Smets, J.; Armes, S. P. Bespoke cationic nano-objects via RAFT aqueous dispersion polymerisation. Polym. Chem. 2016, 7, 3864-3873.

(45) Byard, S. J.; Blanazs, A.; Miller, J. F.; Armes, S. P. Cationic Sterically Stabilized Diblock Copolymer Nanoparticles Exhibit Exceptional Tolerance toward Added Salt. Langmuir 2019, 35, $14348-14357$.

(46) Karjalainen, E.; Aseyev, V.; Tenhu, H. Influence of Hydrophobic Anion on Solution Properties of PDMAEMA. Macromolecules 2014, 47, 2103-2111.

(47) Karjalainen, E.; Aseyev, V.; Tenhu, H. Counterion-Induced UCST for Polycations. Macromolecules 2014, 47, 7581-7587.

(48) Baddam, V.; Aseyev, V.; Hietala, S.; Karjalainen, E.; Tenhu, H. Polycation-PEG Block Copolymer Undergoes Stepwise Phase Separation in Aqueous Triflate Solution. Macromolecules 2018, 51, 9681-9691.

(49) Karjalainen, E.; Suvarli, N.; Tenhu, H. Thermoresponsive Behavior of Poly[Trialkyl-(4-Vinylbenzyl)Ammonium] Based Polyelectrolytes in Aqueous Salt Solutions. Polym. Chem. 2020, 11, 58705883.

(50) Byard, S. J.; Williams, M.; McKenzie, B. E.; Blanazs, A.; Armes, S. P. Preparation and Cross-Linking of All-Acrylamide Diblock Copolymer Nano-Objects via Polymerization-Induced Self-Assembly in Aqueous Solution. Macromolecules 2017, 50, 1482-1493.

(51) Figg, C. A.; Carmean, R. N.; Bentz, K. C.; Mukherjee, S.; Savin, D. A.; Sumerlin, B. S. Tuning Hydrophobicity To Program Block Copolymer Assemblies from the Inside Out. Macromolecules 2017, 50, 935-943.

(52) Mukherjee, S.; Bapat, A. P.; Hill, M. R.; Sumerlin, B. S. Oximes as Reversible Links in Polymer Chemistry: Dynamic Macromolecular Stars. Polym. Chem. 2014, 5, 6923-6931.

(53) Ma, Y.; Gao, P.; Ding, Y.; Huang, L.; Wang, L.; Lu, X.; Cai, Y. Visible Light Initiated Thermoresponsive Aqueous Dispersion Polymerization-Induced Self-Assembly. Macromolecules 2019, 52, 1033-1041.

(54) Zhou, W.; Qu, Q.; Xu, Y.; An, Z. Aqueous PolymerizationInduced Self-Assembly for the Synthesis of Ketone-Functionalized Nano-Objects with Low Polydispersity. ACS Macro Lett. 2015, 4, 495-499.

(55) Skrabania, K.; Miasnikova, A.; Bivigou-Koumba, A. M.; Zehm, D.; Laschewsky, A. Examining the UV-Vis Absorption of RAFT Chain Transfer Agents and Their Use for Polymer Analysis. Polym. Chem. 2011, 2, 2074-2083.

(56) Wang, X.; Zhou, J.; Lv, X.; Zhang, B.; An, Z. TemperatureInduced Morphological Transitions of Poly(Dimethylacrylamide)Poly(Diacetone Acrylamide) Block Copolymer Lamellae Synthesized via Aqueous Polymerization-Induced Self-Assembly. Macromolecules 2017, 50, 7222-7232.

(57) He, W.-D.; Sun, X.-L.; Wan, W.-M.; Pan, C.-Y. Multiple Morphologies of PAA-b-PSt Assemblies throughout RAFT Dispersion Polymerization of Styrene with PAA Macro-CTA. Macromolecules 2011, 44, 3358-3365.

(58) Cong, Y.; Zhou, Q.; Chen, B.; Fang, J.; Fu, J. Morphological Transformations of Nonequilibrium Assemblies of Amphiphilic Diblock Copolymer. Colloid J. 2014, 76, 774-781.

(59) Shan, J.; Chen, J.; Nuopponen, M.; Tenhu, H. Two Phase Transitions of Poly(N-Isopropylacrylamide) Brushes Bound to Gold Nanoparticles. Langmuir 2004, 20, 4671-4676.

(60) Ren, H.; Qiu, X.-P.; Shi, Y.; Yang, P.; Winnik, F. M. The Two Phase Transitions of Hydrophobically End-Capped Poly(NIsopropylacrylamide)s in Water. Macromolecules 2020, 53, 51055115. 